www.jmscr.igmpublication.org

Impact Factor (SJIF): 6.379

Index Copernicus Value: 79.54

ISSN (e)-2347-176x ISSN (p) 2455-0450

crossrefDOI: https://dx.doi.org/10.18535/jmscr/v6i11.36

\title{
Autoimmune Encephalitis-A Rare Case Report
}

\author{
Authors \\ Dr Sayali Kusalkar, Dr Kishor Jadhav, Dr Aarti Kulkarni, Dr Jaishree Ghanekar
}

\begin{abstract}
Patient 29/ Female admitted with complaints of fever with chills, altered sensorium and nausea since 2 days. Complete fever profile negative.MRI CSF studies done normal. Patient throwed focal seizures with general examination normal and systemic examination showed no neurodeficit. Twice MRI and CSF done normal. With HSv-PCr Negative. EEG done s/o Continuous slow waves showing generalized theta to delta range slowing with serrated appearance of delta waves (due to overriding fast beta activity) in frontal area representing extreme delta brush. ANTI-TPO antibodies, Thyroglobulin antibodies was negative NMDA receptor antibody was negative. All these symptoms fitted under category of autoimmune encephalitis. Patient improved with injectable and oral steroids.

Keywords: autoimmune, delta, focal, seizures.
\end{abstract}

\section{Introduction}

Autoimmune encephalitis refers to a group of conditions that occur when the body's immune system mistakenly attacks healthy brain cells, leading to inflammation of the brain. People with autoimmune encephalitis may have various neurologic and/or psychiatric symptoms. Neurologic symptoms may include impaired memory and cognition, abnormal movements, seizures, and/or problems with balance, speech, or vision. Psychiatric symptoms may include psychosis, aggression, inappropriate sexual behaviors, panic attacks, compulsive behaviors, euphoria or fear. Symptoms may fluctuate, but often progress over days to a few weeks. Symptoms can progress to loss of consciousness or even coma.

\section{Case Report}

Female pt 29 years old, recently married, presented to emergency with the complaints of fever with chills, altered sensorium, nausea since 2 days. No history of seizures with these complaints patient was previously taken to a local hospital where patient was evaluated with complete fever profile which was negative. MRI brain \& CSF study was done which showed normal results. On Examination General condition moderate afebrile pulse rate 78 beats per minute blood pressure $104 / 70 \mathrm{mmhg}$ saturation $97 \%$ on ambient air capillary blood sugar $118 \mathrm{mg} / \mathrm{dl}$. System examination- CNS examinationconscious but disoriented to time and place cranial nerves - normal no motor deficit sensory system normal pupils - bilateral reacting to light plantars - extensors no signs of meningeal irritation Other systemic examination was normal. Investigations-Fever profile was done - widal 
titre (s. typhi - 1:80) other fever profile was negative. Repeat Mri brain and Csf study was normal including Hsv-Dna-pcr test.In view of persistent fever and altered sensorium ct scan of chest, abdomen and pelvis was done to rule out possibilty of tuberculosis:- possibility of focal seizures myoclonic jerks psychiatric/hysterical manifestations.06/07/2018: H/o - Focal facial twitching, Confusion, Disorientation to place and person, Perplexity, Total Amnesia for preceding events \& SECONDARY ANXIETY for which TAB CLONAZEPAM $\quad 0.5 \mathrm{mg} \quad 1 / 2$ tablet was added.07/07/2018: Patient improved with patchy recollection of previous day's events. However, she showed altered behaviour in form of spontaneity, circumstantiality, pressure of speech, reduced sleep \& occasional facial twitches. TAB QUETIAPINE 25mg 1-1-2 was added for symptomatic relief.11/07/2018: Patient recovered totally. TAB QUETIAPINE stopped and TAB CLONAZEPAM tapered off gradually.Patient was treated empirically with Third generation cephalosporins I.v. acyclovir but there was no improvement.Anti-TPO antibodies, Throglobulin antibodies, NMDA receptor antibodies negative.EEG was done s/o Continuous slow waves showing generalized theta to delta range slowing with serrated appearance of delta waves (due to overriding fast beta activity) in frontal area representing extreme delta brush. Patient was diagnosed with autoimmune encephalitis treated with i.v. steroids (methylprednisolone) i.v. antiepileptic drugs .She improved gradually over a period of week and was discharged on oral steroids in tapering dose.Patient is doing well on follow.

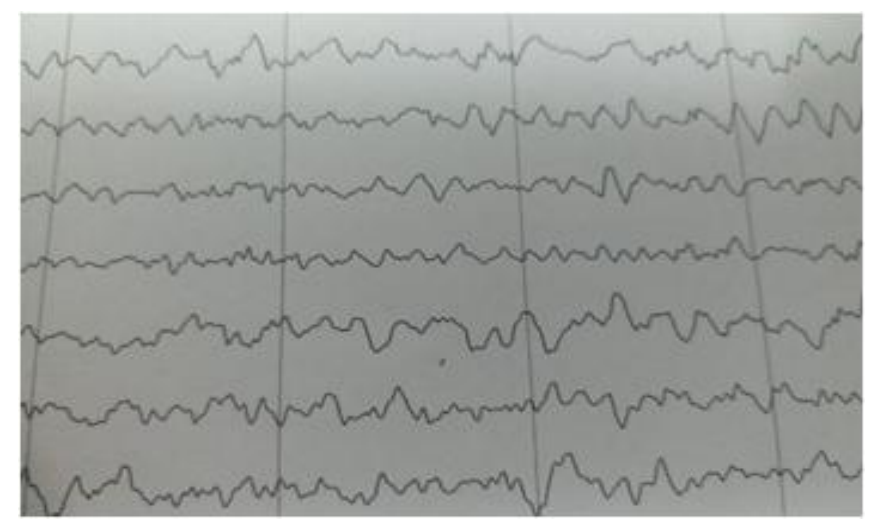

\section{Discussion}

Diagnosis of autoimmune encephalitis can be made when all three of the following criteria have been met:

1. Subacute onset (rapid progression of less than 3 months) of working memory deficits (short-term memory loss), altered mental status, or psychiatric symptoms

2. At least one of the following:

- New focal CNS findings

- Seizures not explained by a previously known seizure disorder

- CSF pleocytosis (white blood cell count of more than five cells per mm3)

- MRI features suggestive of encephalitis

3. Reasonable exclusion of alternative causes

Classification Autoimmune encephalopathies without malignancy. Paraneoplastic encephalopathies Vasculitis associated encephalopathy

Acute treatment -IV Methylprednisolone 1gm IV Daily for 3-5 days and then weekly for 6-8 weeksORIntravenous Immunoglobulin $0.4 \mathrm{gm} / \mathrm{kg}$ Iv Daily for 3-5 days and then weekly for 6-8 weeks OR Plasma exchange (severe attacks, incomplete response to steroids).

\section{References}

1. J. Dalmau, A. J. Gleichman, E. G. Hughes et al., "Anti-NMDA-receptor encephalitis: case series and analysis of the effects of antibodies," The Lancet Neurology, vol. 7, no. 12, pp. 1091-1098, 2008.

2. K.-P. Wandinger, S. Saschenbrecker, W. Stoecker, and J. Dalmau, "Anti-NMDAreceptor encephalitis: a severe, multistage, treatable disorder presenting with psychosis," Journal of Neuroimmunology, vol. 231, no. 1-2, pp. 86-91, 2011.

3. M. J. Titulaer, L. McCracken, I. Gabilondo et al., "Treatment and prognostic factors for long-term outcome in patients with anti-NMDA receptor encephalitis: an observational cohort study," The Lancet 
Neurology, vol. 12, no. 2, pp. 157-165, 2013.

4. E. Maneta and G. Garcia, "Psychiatric manifestations of Anti-NMDA receptor encephalitis: neurobiological underpinnings and differential diagnostic implications," Psychosomatics, vol. 55, no. 1, pp. 37-44, 2014

5. M. S. Kayser, M. J. Titulaer, N. GresaArribas, and J. Dalmau, "Frequency and characteristics of isolated psychiatric episodes in anti-N-methyl-D-aspartate receptor encephalitis," JAMA Neurology, vol. 70, no. 9, pp. 1133-1139, 2013. 